\title{
Treatment of Primary Tumour in Prostate Cancer Metastatic Disease: A Different Method of Clinical Management
}

\author{
Goonewardene, S.S ${ }^{1^{*}}$, Persad, $\mathbf{R}^{2}$ \\ ${ }^{1}$ Guys Hospital, Kings College London \\ ${ }^{2}$ North Bristol NHS Trust
}

*Corresponding author: Goonewardene, S.S, Guys Hospital, Kings College London; E-mail: ssg7727@yahoo.co.uk

Received Date: November 05, 2015 Accepted Date: November 26, 2015 Published Date: November 30, 2015

Citation: Goonewardene, S.S, et al. Treatment of Primary Tumour in Prostate Cancer Metastatic Disease: A Different Method of Clinical Management. (2015) Intl J Cancer Oncol 2(3): 1-2.

Keywords: Metastatic prostate cancer; Treatment of primary tumour

DOI: $10.15436 / 2377-0902.15 . e 005$

Dear Sir,

There have been a number of articles recently, addressing treatment of the primary prostate tumour in presence of metastases. This is clearly a very important unaddressed topic, which impacts significantly on our management.

A retrospective multi-institutional analysis of radical prostatectomy (RP) alone ${ }^{[1]}$, looking at 345 patients with T3 disease, found a $10-y r$ disease free survival rate of only $57 \%{ }^{[2]}$. For patients with well-differentiated, moderately differentiated, and poorly differentiated tumours, were $73 \%, 67 \%$, biochemically free survival rates were and $29 \%$, respectively ${ }^{[3]}$.

When RT (radiotherapy) and RP are used in combination, survival rates exceed those for RT alone and compared to those post androgen-deprivation therapy and external beam RT (Bolla historical series; 5-yr OS 78\%) ${ }^{[4]}$. RP has a place in the treatment of locally advanced prostate cancer is supported by a few studies recently conducted in the United States ${ }^{[5]}$. RP, combined with adjuvant or salvage treatment when needed, may result in better outcomes than RT alone, similar to the combination of RT plus HT therapy. There is ongoing controversy- this is a historical comparison.

$\mathrm{RP}$ has a place in the treatment of locally advanced prostate cancer is supported by a few studies recently conducted in the United States ${ }^{[5]}$. RP, combined with adjuvant or salvage treatment when needed, may result in better outcomes than RT alone, similar to the combination of RT plus HT therapy.

There is a constant ongoing controversy, whether cytoreductive surgery in these cases, will benefit the patient. However, Culp found there was a survival benefit conferred. This high risk surgery, will almost always involve multimodal therapy therefore compounding side effects from hormone and radiotherapy.

The basis of cytoreductive surgery is resection of the primary tumour mass. This results in less tumour cell shedding, and reduction in tumour-associated growth factors from the primary tumour ${ }^{[6]}$. The question arises, whether we should be performing bilateral pelvic lymphadenopathy-both from a prognostic and therapeutic viewpoint. These issues which are contentious are based on prognostic and therapeutic studies. We owe it to our patients of future. The problem here, are that most of these series are retrospective and from the studies which have been done the sample sizes are relatively small. In addition, there are no criteria present, to identify patients most likely to benefit from therapy ${ }^{[7]}$.

In conclusion, these questions that remain unanswered, point towards a requirement for a trial.

With kind regards,

Copy rights: (C2015 Goonewardene, S.S. This is an Open access article distributed under the terms of Creative Commons Attribution 4.0 International License. 


\section{References}

1. Heidenreich, A., Pfister, D., Porres, D. Cytoreductive Radical Prostatectomy in Patients with prostate cancer and low volume skeletal metastases - results of a feasibility and case-control study. (2014) J Urol 193(3): 832-838.

2. Van Den Ouden, D., Hop, W.C., Schroder, F.H. Progression in and survival of patients with locally advanced prostate cancer (T3) treated with radical prostatectomy as monotherapy. (1998) J Urol 160(4):1392-1397.

3. Gerber, L., Banez, L.L., Freedland, S.J. Defining and Treating High-Risk Prostate Cancer: Can We Do Better? (2010) European Urology 58(1): 8-11.
4. Lange, P.H. Is Surgery Good for Advanced Localised Prostate Cancer? It's Time to Find Out! (2007) European Urology 51(4): 873-875.

5. Abern, M.R., Aronson, W.J., Terris, M.K., et al. Delayed radical prostatectomy for intermediate-risk prostate cancer is associated with biochemical recurrence: Possible implications for active surveillance from the SEARCH database. (2013) Prostate 73(4): 409-417.

6. Stenzl, A., Merseburger, A.S. Radical Prostatectomy in Advanced-Stage and -Grade Disease: Cure, Cytoreduction, or Cosmetics? (2008) European Urology 53(2): 234-236.

7. Ito, H., Shioi, K., Murakami, T., et al. C-reactive protein in patients with advanced metastatic renal cell carcinoma: Usefulness in identifying patients most likely to benefit from initial nephrectomy. (2012) BMC Cancer 12: 337. 